Çukurova Üniversitesi Mühendislik Mimarlık Fakültesi Dergisi, 35(1), ss. 251-262, Mart 2020

Çukurova University Journal of the Faculty of Engineering and Architecture, 35(1), pp. 251-262, March 2020

\title{
Dökme Demir Malzemelerin Karbür Uçlarla Delme İşleminde Proses Parametrelerinin Optimizasyonu
}

\author{
Onur ERTUĞRUL ${ }^{1}$, Oğuzcan GÜZELİPEK ${ }^{* 2}$, Tuğrul SOYUSİNMEZ ${ }^{3}$, \\ Ali Tuğberk AKDOĞAN ${ }^{4}$, Aziz Burak GÜNEŞ ${ }^{4}$ \\ ${ }^{1}$ İzmir Katip Çelebi Üniversitesi, Mühendislik ve Mimarlık Fakültesi, Malzeme Bilimi ve \\ Mühendisliği Bölümü, İzmir \\ ${ }^{2}$ Totomak Makina ve Yedek Parça Sanayi ve Ticaret A.Ş, İzir \\ ${ }^{3}$ Gazi Üniversitesi, Teknoloji Fakültesi, Endüstriyel Tasarım Mühendisliği Bölümü, Ankara \\ ${ }^{4}$ Çukurova Üniversitesi, Mühendislik Fakültesi, Otomotiv Mühendisliği Bölümü, Adana
}

Geliş tarihi: 26.02.2020 Kabul tarihi: 15.05 .2020

$\ddot{O} z$

Takım aşınmalarının, parça üretim maliyeti ve üretim verimliliğine doğrudan etkisi mevcuttur. Takımlarda meydana gelen aşınmalar, üretim kalitesini doğrudan etkileyen bir faktördür. Bu çalışmada, farklı matkap çapları ve kesme parametrelerinin takım aşınmasına etkisi araştırılmıştır. Deneyler, farklı çapta matkaplar ve farklı kesme parametreleri ile 9 farklı kombinasyonda 20 tekrar seklinde yapılmıştır. Deneysel çalı̧̧mada imalat sektöründe sıkça kullanılan $6,8 \mathrm{~mm}, 9 \mathrm{~mm}$ ve $9,6 \mathrm{~mm}$ çapa sahip yekpare karbür matkap uçlar kullanılmıştır. İş parçası olarak üretimde sıkça kullanılmakta olan GG25 ve GGG40 standartlı dökme demir malzemeler belirlenmiştir. Taguchi tekniği kullanılarak en yüksek takım ömrü değerlerini veren optimum kontrol faktörleri belirlenmiştir. Ayrıca her deneyden sonra matkap uçlarındaki aşınma durumları ve tipleri takım ölçme ve ayarlama makinası yardımı ile tespit edilmiştir. GGG40 malzemenin GG25 standartlı malzemeye göre, matkap ucunda daha çok aşınmaya sebebiyet verdiği ve matkap ucunun çapı arttıkça aşınma miktarlarında da arttığı belirlenmiştir.

Anahtar Kelimeler: Matkap ucu, Karbür Takım, Takım aşınması, Aşınma tipleri, Taguchi metodu

\section{Optimization of Process Parameters in Drilling of Cast Iron Materials with Carbide Drills}

\begin{abstract}
There is a direct relationship between tool wear and part production cost efficiency. Wear on the tools is a main factor that directly affects the quality of production. In this study, the effect of different diameters of drill and cutting parameters on tool wear was investigated. 20 test repetitions were performed with 9 different combinations of tools with different diameters and different cutting parameters. The effects of parameters on tool wear were observed. Solid carbide tools with a diameter of $6.8 \mathrm{~mm}, 9 \mathrm{~mm}$ and $9.6 \mathrm{~mm}$ and cast iron materials of GG25 and GGG40 standard were used as work pieces in experimental studies. The design of the experiment was determined by Taguchi method and after each experiment, the wear conditions and types of drill bits were by using of a tool measurement and adjustment machine. It has been determined that GGG40 material causes more wear on the drill bit compared to the GG25 standard material and increases the amount of wear as the diameter of the drill bit increases.
\end{abstract}

Keywords: Drill bit, Carbide tools, Tool wear, Wear types, Taguchi method

*Sorumlu yazar (Corresponding author): Oğuzcan GÜZELİPEK, oguzcan.guzelipek@gmail.com 


\section{GíRiş}

Son zamanlarda imalat sektöründeki gelişen teknolojiler ve CNC (Computer Numeric Control) kullanımı sayesinde otomasyona geçilmesine rağmen kesme ve delik delme operasyonlarında hala çözülememiş problemler mevcuttur. Kesici takımın aşınması ve kırılması bu duruma en iyi örnektir. Aşınma, malzemelerin yüzeyinden mekanik etkiler nedeni ile değişik boyutlarda parçacıkların istenmeyen şekilde ayrılması sebebiyle oluşan değişiklik ya da değişiklikler olarak tanımlanır. Bununla beraber, eskimeye sebep olan elektriksel, fiziksel ve kimyasal etkenlerle yüzeyden büyük boyuttaki parçaların kırılması da aşınma kavramı içerisinde yer alır. Belirli bir seviyeden sonra kesici takımın artan aşınma miktarı ile (özellikle yan yüzey aşınması) takıma etki eden direnç kuvvetleri ve talaş kaldırma kuvvetleri artar ve bu da kırılmaya sebep olmaktadır. $\mathrm{Bu}$ durum operatöre, tezgâha ve iş parçasına, kırılan matkap ucunun yüksek hızlarda çarpması ile büyük zararlar verebilmektedir. Ayrıca, aşınmayla birlikte beklenen yüzey kalitesi ve hassasiyeti elde edilemez. Kesme işlemi sırasında meydana gelen kuvvet, sürtünme, 1sı gibi etkenlerden dolayı kesici takım uçlarında ve yan yüzeylerinde aşınmaya yol açacaktır ve bu aşınmalar yüzey kalitesinde istenmeyen bozukluklara yol açacaktır. $\mathrm{Bu}$ yüzden, bilenmeyen ya da değiştirilmeyen kesici takım üretim ve takım maliyetlerinin artışına sebebiyet verecektir [1].

Kesici takımların ömrü bittikten sonra değiştirilmelidir. Bunun için takımların ömrünü bilmek gerekmektedir. Talaş kaldırma sırasında kesme parametrelerinin ve değişken yüklerin kesici uçların ömrünü nasıl etkilediğinin araştırıldığı bir çalışmada; sabit ve değişken yük şartları altında talaş kaldırma işlemleri uygulanmıştır. Test sistemi ile etki eden kesme kuvvetleri ölçülmüş ve kesici uç aşınmaları incelenerek takım ömürleri hesaplanmıştır. Sonuç olarak, kesme hızı artışı ve değişken yüklemelerin takım ömrünü kötü etkilediği görülmüştür [2]. Her takımın malzemesi ve bu malzemelerin aşınma durumları aynı olmadığından dolayı ömrü farklıdır. $\mathrm{Bu}$ yüzden, takımın ömrünü hesaplamak için yapılan deneylerde farklı kesme parametrelerinde (ilerleme miktarı, kesme derinliği, kesme hızı, vb.) kesici uçların ömürleri belirlenir ve en iyi sonucu veren kesme parametresinin işlenen parça üzerinde oluşturacağ 1 yüzey pürüzlülüğü bilinmelidir. İşlenen parçaların istenilen verimde çalışabilmesi için en önemli etkenlerden biri parça yüzey kalitesidir ve belirlenmesinde yüzey pürüzlülüğü faktörü kullanılır. Yüzey pürüzlülüğünü kesme hızı, ilerleme miktarı ve kesme derinliği gibi parametreler doğrudan etkiler [3,4]. Kesme şartları iyi belirlenemediği zaman, yorulma ve korozyon dayanımının azalmasına, çentik etkisine neden olarak çatlaklar oluşmasına ve yüzey kalitesinin kötüleşmesine sebep olmaktadır. Gelişmiş ülkelerin bile aşınma ile ortaya çıkan zararın ekonomik değerinin o ülkenin GSMF'nın \%7'sine eşdeğer olduğu ön görülmektedir [5].

Deney tasarımında faktör ve faktör seviyeleri arttıkça deney sayısı da artmaktadır. Bu durum deney maliyetlerinin artmasina ve deney sürelerinin uzamasına neden olmaktadır. Bu sorunu çözmek için kesirli faktöriyel deney tasarımı geliştirilmiştir. Kesirli deney tasarımı deney sayılarını azaltmakla birlikte farklı araştırmacıların aynı kesirli deneylerde farklı seviye seçebilmeleri nedeniyle farklı sonuçlar elde etmelerine neden olmaktadır. Bu sorunu Genichi Taguchi geliştirmiş olduğu standart ortogonal diziler ile çözmüştür. Böylelikle farklı araştırmacılar aynı faktör ve seviyeleri için aynı ortogonal çizelgeleri kullanma imkanı bulmuştur. Genichi Taguchi tarafından geliştirilmiş olan bu yönteme Taguchi Metodu denmektedir. Deneysel tasarımdan farklı olarak Taguchi Metodu, deney faktörlerini kontrol edilebilir ve kontrol edilemez faktörler olarak ikiye ayırmıştır. Taguchi, kontrol edilemeyen ya da kontrolü zor faktörlerin deney çıktılarına etkilerini azaltmak için üç adet logaritmik Sinyal/Gürültü (Signal to Noise) fonksiyonu geliştirmiştir. Fonksiyonun seçimi: Deneyde istenen çıktıların durumuna göre en küçük-en iyi, en büyük-en iyi ve nominal-en iyi olacak şekilde uygun fonksiyon seçilir. Örneğin 
yüzey pürüzlülüğü deneylerinde en küçük-en iyi fonksiyon seçilmektedir. Taguchi $\mathrm{S} / \mathrm{N}$ fonksiyonlarının kullanılabilmesi için kontrol edilemeyen faktörlerin en az iki tekrarlı yapılması gerektiğini belirtmiştir [6-9].

Deney tasarımının amacı ulaşılmak istenen veya araştırılmak istenen sonuçların ve bu sonuçlardan ortaya çıkan sapmaların doğru bir şekilde analiz etmek için kullanılan deney grubunu planlamaktır. Deney tasarım yöntemleri yalnızca istatiksel yaklaşım değildir. Tüm Ar-Ge çalışmalarında kullanılabilir, kalite arttıran, maliyetleri en aza indiren, verilerin doğruluğunu sağlamlaştıran, tüm kalite tekniklerini destekleyen ve tamamlayan tekniklerden oluşmaktadır [10]. Deney tasarımlarının uygulamada sundukları avantajlar ürün kalitesinde ve performansında artış olması, elde olan kaynakların daha verimli kullanılması, Ar-Ge çalışmalarında zamandan tasarruf sağlanması, ürünün veya sürecin kalitesel özelliklerini iyileştirilmesi şeklinde sıralanabilir. Deney tasarımı metotları yüz yılbaşında tarımsal çalışmalarda kullanılarak Fischer tarafindan geliştirilmiştir [11]. Ancak bu tarz deney tasarım modelleri endüstriyel alanlarda başarılı olamayan modellerdir.

Sistemin karmaşıklaşması ile artan unsurların sayıs1 yapılmas1 gereken test sayısinı da arttırmaktadır. Genichi Taguchi, ismi ile bütünleşen yöntemi ile deneylerin yapılması ve değerlendirilmesinde verimliliği arttıran bir çözüm geliştirmiştir [12]. .Bu çözüm sayesinde önceden yapılmış detaylı bir analiz ve değerlendirme ile birlikte deney sayısı önemli ölçüde azalmış olur.

Diğer kesme operasyonlarındaki gibi delme operasyonlarında da kesici takımın aşınmasının operasyon esnasında gözlemlenmesi ve kalıcı bir hasardan önce süreci durdurarak oluşmuş sorunun giderilmesi, çözüme kavuşması gereken bir problem olmuştur. Tam otomasyon ile çalışan üretim tesislerinde takımların aşınmasını operasyon esnasında gözlemlemek, aşınan matkap takımının kırılmadan önce değiş̧irilip, malzeme üzerindeki problemi yok etme bakımından oldukça önem sarf eden bir husustur. Torna, delik delme, taşlama gibi metal şekillendirme ve kesme operasyonları içerisinde, uygulanan işlemlerin tekrarı dikkate alındığında, matkap ile delme işlemi bu operasyonlar içerisinde en büyük öneme sahip olup, delme işlemi, genellikle başka bir kesme operasyonunun da ilk adımını oluşturmaktadır. Aynı zamanda en fazla kullanılan operasyonlardan birisidir. Delik delme işlemi, genelde talaşlı imalat prosesinin son aşamasıdır.

Matkap etrafinda meydana gelen metal talaş1 kalınlığı, iş parçası talaşının akışını belirleyen bir faktördür. Matkap ile iş parçası arasında oluşan sürtünme sonucu yüzeyde oluşan sıcaklığın yetersiz ve dönme ekseninde kesme hızının sıfır olması, delik delme işlemindeki en büyük sorundur. Bunun üzerine matkap formunu ve malzemelerin iyileştirilmesi ile ilgi araştırmalar ve çalışmalar yapılmaktadır [5].

Matkap ile delme operasyonu, talaşlı imalat operasyonları içerisinde en sik kullanılan operasyonlardan biridir ve talaş kaldırma operasyonlarının yaklaşık \%33'ünü oluşturur. Ayrıca, delik delme işlemlerinde yaklaşık \%25'e yakın bir zaman harcanmaktadır. Dolayısıyla, delik delme operasyonunda sağlanabilecek performans iyileştirmeleri (parametrelerin optimizasyonu ve matkap takımlarının veriminin arttrılması) maliyetlere ve niteliklerine önemli derecede fayda sağlayacaktır. Bu bağlamda geliştirilen en verimli metot, taban malzeme olarak uzun süredir kullanılmakta olan ve seçilen yüksek hız çeliklerinin özelliklerini ince sert seramik kaplamalar ile desteklemektir. Özellikle TiN ve TiAIN kaplamaların sıklıkla kullanılmaya başlanmasına rağmen, kaplanmamış matkap takımlarına kıyasla bu kazanımlarının açık şekilde ortaya konmasında hala eksikler vardır. Doğru kaplama seçimi ile beraber en uygun değerli kesme ve ilerleme hızlarının belirlenmesi de aşınma miktarlarının azalmasına ve endüstriyel işletmelerde verimliliğin artmasına sebep olacaktır [10].

İlhan ve arkadaşının Taguchi metoduyla yaptı̆̆ çalışmada optimum kesme parametrelerini belirlenmiş ve sonuçlar Varyans Analizi ile değerlendirilmiştir. S/G oranına Varyans Analizi 
uygulanarak kesme parametreleri ve yüzey pürüzlülüğü arasındaki etkileşim incelenmiştir. Analize göre besleme oranının yüzey pürüzlülüğüne etkisi \%95 olarak belirlenmiștir [13].

Yapılan bir başka çalışmada Tugay ve arkadaşları AISI 316 paslanmaz çelik üzerinde en uygun kesme değişkenlerini belirlemek için Taguchi metodu kullanılmıştır. Çalışma sonuçları Varyans Analizi ile değerlendirilmiştir. Yüzey pürüzlülüğünü etkileyen en önemli unsur \%39,14 yüzdeyle kesme aleti olarak belirlenmiştir ve besleme oranının \%82,77 yüzdesiyle itme kuvvetini etkilediği belirlenmiştir. Optimum kombinasyonlarda yüzey pürüzlülüğü ile alakalı kalite kayıpları çok düşük (\%6) olduğu gözlenmiştir [14].

Bu çalışma, Taguchi metodu ile deney tasarımı yapılan, sik kullanılan metal kesme operasyonlarından olan delik delme operasyonunda kullanılan karbür esaslı kesici takım uçlarının dökme demir malzemeleri delme işleminde; her deneyden sonra takım ölçme ve ayarlama makinasında incelendikten sonra aşınma durumunun ve tiplerinin belirlenmesini ve deneysel tasarım sonrasındaki delik delme işlemlerinin analizlerinin yapılmasını amaçlamaktadır.

\section{MALZEME VE YÖNTEM}

\subsection{Kullanılan Malzemeler ve Ekipman}

Deneylerde kullanılan iş parçaları, yarı hammadde olarak üretilip TOTOMAK A.Ş.'de işlenen lamel grafitli dökme demir (GG25) ve küresel grafitli dökme demir (GGG40) malzemelerdir. $\mathrm{Bu}$ malzemelerin seçilmesinin sebebi karbür matkap uçları ile işlenebilirliğinin yüksek olmasıdır. Çizelge 1 ve Çizelge 2'de GG25 standartlı malzemenin mekanik ve kimyasal özellikleri verilmiştir. Çizelge 3 ve Çizelge 4'te ise GGG40 standartlı malzemenin mekanik ve kimyasal özellikleri görülmektedir.
Çizelge 1. GG25 standartlı malzemenin mekanik özellikleri

\begin{tabular}{|l|c|c|c|}
\hline $\begin{array}{l}\text { Çekme } \\
\text { Mukavemeti }\end{array}$ & $\sigma_{\mathrm{m}}$ & 250 & {$\left[\mathrm{~N} / \mathrm{mm}^{2}\right]$} \\
\hline $\begin{array}{l}\text { Akma } \\
\text { Mukavemeti }\end{array}$ & $\sigma_{0.20 \mathrm{~B}}$ & 163 & {$\left[\mathrm{~N} / \mathrm{mm}^{2}\right]$} \\
\hline Brinell Sertliği & $\mathrm{HB}_{30}$ & $180-240$ & {$\left[\mathrm{Kg} / \mathrm{mm}^{2}\right]$} \\
\hline Elastik Modülü & $\mathrm{E}_{\mathrm{o}}$ & 120 & {$\left[\mathrm{~N} / \mathrm{mm}^{2}\right]$} \\
\hline $\begin{array}{l}\text { Yorgunluk } \\
\text { Sınırı }\end{array}$ & $\mathrm{R}_{\mathrm{m}}$ & 115 & {$\left[\mathrm{~N} / \mathrm{mm}^{2}\right]$} \\
\hline Darbe Dayanımı & $\mathrm{Av}$ & 28 & {$[\%]$} \\
\hline $\begin{array}{l}\text { Sıkıştırma } \\
\text { Dayanımı }\end{array}$ & $\sigma_{\mathrm{dB}}$ & 950 & {$\left[\mathrm{~N} / \mathrm{mm}^{2}\right]$} \\
\hline
\end{tabular}

Çizelge 2. GG25 standartlı malzemenin kimyasal özellikleri

\begin{tabular}{|l|c|l|c|}
\hline Karbon & $\mathrm{C}$ & $2,9-3,65$ & {$[\%]$} \\
\hline Silisyum & $\mathrm{Si}$ & $1,8-2,9$ & {$[\%]$} \\
\hline Magnezyum & $\mathrm{Mn}$ & $0,5-0,7$ & {$[\%]$} \\
\hline Sülfür & $\mathrm{S}$ & 0,10 maks. & {$[\%]$} \\
\hline Fosfor & $\mathrm{P}$ & 0,30 maks. & {$[\%]$} \\
\hline Demir & $\mathrm{Fe}$ & Geriye kalan \\
\hline
\end{tabular}

Çizelge 3. GGG 40 standartlı malzemenin mekanik özellikleri

\begin{tabular}{|l|c|c|c|}
\hline $\begin{array}{l}\text { Çekme } \\
\text { Mukavemeti }\end{array}$ & $\sigma_{\mathrm{m}}$ & 400 & {$\left[\mathrm{~N} / \mathrm{mm}^{2}\right]$} \\
\hline $\begin{array}{l}\text { Akma } \\
\text { Mukavemeti }\end{array}$ & $\sigma_{0.20 \mathrm{~B}}$ & 250 & {$\left[\mathrm{~N} / \mathrm{mm}^{2}\right]$} \\
\hline $\begin{array}{l}\text { Brinell } \\
\text { Sertliği }\end{array}$ & $\mathrm{HB}_{30}$ & $135-180$ & {$\left[\mathrm{Kg} / \mathrm{mm}^{2}\right]$} \\
\hline $\begin{array}{l}\text { Esneklik } \\
\text { Modülü }\end{array}$ & $\mathrm{E}_{\mathrm{o}}$ & 169 & {$\left[\mathrm{~N} / \mathrm{mm}^{2}\right]$} \\
\hline $\begin{array}{l}\text { Yorgunluk } \\
\text { Sınırı }\end{array}$ & $\mathrm{R}_{\mathrm{m}}$ & 220 & {$\left[\mathrm{~N} / \mathrm{mm}^{2}\right]$} \\
\hline $\begin{array}{l}\text { Darbe } \\
\text { Dayanımı }\end{array}$ & $\mathrm{Av}$ & 10 & {$[\mathrm{Joule}]$} \\
\hline $\begin{array}{l}\text { Sıkıstırma } \\
\text { Dayanımı }\end{array}$ & $\sigma_{\mathrm{dB}}$ & 800 & {$\left[\mathrm{~N} / \mathrm{mm}^{2}\right]$} \\
\hline
\end{tabular}


Çizelge 4. GGG 40 standartlı malzemenin kimyasal özellikleri

\begin{tabular}{|l|l|l|l|}
\hline Karbon & $\mathrm{C}$ & $3,4-3,85$ & {$[\%]$} \\
\hline Silisyum & $\mathrm{Si}$ & $2,3-3,1$ & {$[\%]$} \\
\hline Magnezyum & $\mathrm{Mn}$ & $0,1-0,3$ & {$[\%]$} \\
\hline Sülfür & $\mathrm{S}$ & 0,02 maks. & {$[\%]$} \\
\hline Fosfor & $\mathrm{P}$ & 0.10 maks. & {$[\%]$} \\
\hline Demir & $\mathrm{Fe}$ & \multicolumn{2}{|c|}{ Geriye kalan } \\
\hline
\end{tabular}

Bu çalışmada, talaşlı imalatta en çok kullanılan matkaplardan olan iki ağılı helisel, $6,8 \mathrm{~mm}, 9 \mathrm{~mm}$ ve $9,6 \mathrm{~mm}$ çaplı karbür matkap uçları kullanılmıştır. Kullanılan matkap uçlarının teknik özellikleri ve geometrileri Çizelge 5, Çizelge 6 ve Çizelge 7'de verilmiştir.

Çizelge 5. WNT.WPC-UNI.6,80.R.5D.IK.11609068 teknik özellikleri

\begin{tabular}{|c|c|c|c|c|c|}
\hline \multirow{3}{*}{$\leq 5 \times \mathrm{D}$} & \multirow{3}{*}{ शै: } & \multirow{3}{*}{$\begin{array}{c}\Varangle \\
140^{\circ}\end{array}$} & \multirow{6}{*}{ 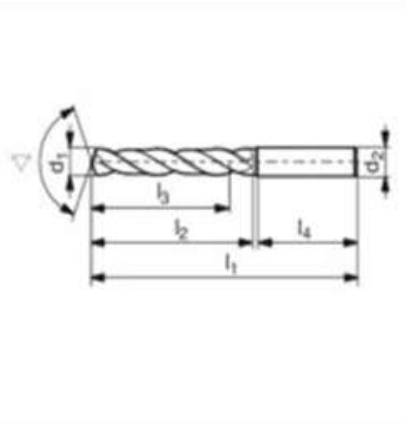 } & $\mathrm{d}_{1 \mathrm{~m}} 7$ & $6,8 \mathrm{~mm}$ \\
\hline & & & & $\underline{d}_{2 b 6}$ & $8 \mathrm{~mm}$ \\
\hline & & & & 11 & $91 \mathrm{~mm}$ \\
\hline \multirow{3}{*}{ TiAIN } & \multirow{3}{*}{ UNI } & \multirow{3}{*}{$\begin{array}{c}\text { DIN } 6535 \\
\text { HA }\end{array}$} & & 12 & $53 \mathrm{~mm}$ \\
\hline & & & & 14 & $36 \mathrm{~mm}$ \\
\hline & & & & 13 & $49 \mathrm{~mm}$ \\
\hline
\end{tabular}

Çizelge 6. WNT.WPC-UNI.9,00.R.5D.IK.11609090 teknik özellikleri

\begin{tabular}{|c|c|c|c|c|c|}
\hline \multirow{3}{*}{$\leq \mathbf{5 x D}$} & & \multirow{3}{*}{$\begin{array}{c}\not{x} \\
140^{\circ}\end{array}$} & \multirow{6}{*}{ (:) } & $\underline{d}_{1 \mathrm{~m}} 7$ & $9 \mathrm{~mm}$ \\
\hline & & & & $\underline{\mathrm{d}}_{2 \mathrm{~b} \sigma}$ & $10 \mathrm{~mm}$ \\
\hline & & & & 11 & $103 \mathrm{~mm}$ \\
\hline \multirow{3}{*}{ TiAIN } & \multirow{3}{*}{ UNI } & \multirow{3}{*}{$\begin{array}{c}\text { DIN } 6535 \\
\text { HA }\end{array}$} & & 12 & $61 \mathrm{~mm}$ \\
\hline & & & & 14 & $40 \mathrm{~mm}$ \\
\hline & & & & 13 & $49 \mathrm{~mm}$ \\
\hline
\end{tabular}

Çizelge 7. WNT.WPC-UNI.9,60.R.5D.IK.11609096 teknik özellikleri

\begin{tabular}{|c|c|c|c|c|c|}
\hline \multirow{3}{*}{$\leq 5 \times \mathrm{xD}$} & \multirow{3}{*}{ पु } & \multirow{3}{*}{$\begin{array}{c}\Varangle \\
140^{\circ}\end{array}$} & \multirow{6}{*}{$(0,5)$} & $\mathrm{d}_{1 \mathrm{~m}} 7$ & $9,6 \mathrm{~mm}$ \\
\hline & & & & $\mathrm{d}_{2 \mathrm{~h} 6}$ & $10 \mathrm{~mm}$ \\
\hline & & & & 11 & $103 \mathrm{~mm}$ \\
\hline \multirow{3}{*}{ TiAIN } & \multirow{3}{*}{ UNI } & \multirow{3}{*}{$\begin{array}{c}\text { DIN } 6535 \\
\text { HA }\end{array}$} & & 12 & $61 \mathrm{~mm}$ \\
\hline & & & & 14 & $40 \mathrm{~mm}$ \\
\hline & & & & 13 & $49 \mathrm{~mm}$ \\
\hline
\end{tabular}


Alınan numunelerin üzerinde delik delme operasyonunu uygulanması için kullanılan matkap tezgahının teknik özellikleri ise Çizelge 8 'de verilmiştir. Matkap tezgâhı kayış kasnak sistemi ile çalışmaktadır.

Çizelge 8. EKÇELİK M-13 (1500) Matkap tezgâhı teknik özellikleri

\begin{tabular}{|l|c|}
\hline Motor Gücü & $0,55 \mathrm{Kw} 1500 \mathrm{~d} / \mathrm{dk}$ \\
\hline Matkap Devri & $4500 \mathrm{devir}$ \\
\hline Bağlanabilecek Maksimum Takım Çapı & $16 \mathrm{~mm}$ \\
\hline Delme Derinlik Mesafesi & $100 \mathrm{~mm}$ \\
\hline Mors Mil Koniği & $\mathrm{B} 16$ \\
\hline Tabla ile Mandren Arasındaki Maks. Yükseklik Mesafesi & $350 \mathrm{~mm}$ \\
\hline Sütun Mili ile Mandren Ucu Mesafesi & $170 \mathrm{~mm}$ \\
\hline Tabla Kullanım Alanı & $245 \times 300$ \\
\hline Tabla T Kanal 3 Adet T Kanal Ölçü & $12 \times 21 \times 19$ \\
\hline
\end{tabular}

\subsection{Taguchi L9 Deney Tasarımı (Design of Experiment With Taguchi L9)}

Taguchi Deney Tasarımı metodu sonucu alınan deney sonuçları signal/noise $(\mathrm{S} / \mathrm{N})$ yani sinyal/gürültü oranına dönüştürülerek değerlendirilir. Bütün $\mathrm{S} / \mathrm{G}$ oranlarında daha büyük olan en iyi deney sonucunu vermektedir. Böylece deneylerde kullanılan faktörlerin seviyelerinden en fazla Sinyal/gürültü oranına sahip değer en iyi performansı verecektir. Bundan ayrı olarak uygulanan varyans analizi (ANOVA) ile hangi işlem üzerinde hangi faktörün daha çok etkili olduğu istatiksel olarak görülebilmektedir. Unsurların birbirine bağlı olmadan değerlendirilebilmesi ve bunun için de unsurların faklı seviyeleri için her test edilen koşulda aynı miktarda örnekleme yapılması dikkat edilmesi gereken bir noktadır [12].

Taguchi Deney Tasarımı metoduna göre bir çalışmada izlenecek adımlar aşağıdaki şekildedir [15]:

1. Faktörlerin seçimi ve aralarındaki etkileşimleri birbirinden bağımsız olarak değerlendirilmesi (sebep sonuç diyagramı, beyin firtınası, akıl diyagramı gibi yöntemler kullanılarak).

2. Faktörler seviyelerinin belirlemek.

3. Doğru ortogonal matrisin seçilmesi.

4. Faktörlerin deney düzenindeki sütunlarla eşleştirmek.

5. Deneylerin önceki basamaklarda belirlenen biçimde uygulamak.

6. Sonuçların analizi (S/G oranı).

7. Onama deneylerinin yapilmasi.

$\mathrm{Bu}$ amaçla, faktörlerin belirlenmesi için yapılan çalışmalar incelenmiş ve takım aşınmasını etkileyen faktörler belirlenmiştir. Seviyeler belirlenirken kullanılan tezgah, üretim sektöründe çok fazla kullanılan takımlar, kesme hızları ve malzemeler göz önünde bulundurularak seçilmiştir. Seviyeler ve faktör çeşitli deney tasarım matrislerini içeren ve Çizelge 9'da gösterilen ortogonal matris seçim çizelgesinden en uygun tasarım matrisi seçilmiştir. Yapılan çalışmada aşınmaya etkileri olan matkap çapı, kesme hızı, ilerleme miktarı faktörlerinin her biri üç seviye belirlenirken malzeme cinsi için seviye belirlenmiştir. Çalışmada kullanılan faktörler ve seviyeler Çizelge 10'da görülmektedir. 
Çizelge 9. Taguchi ortogonal matris seçim çizelgesi

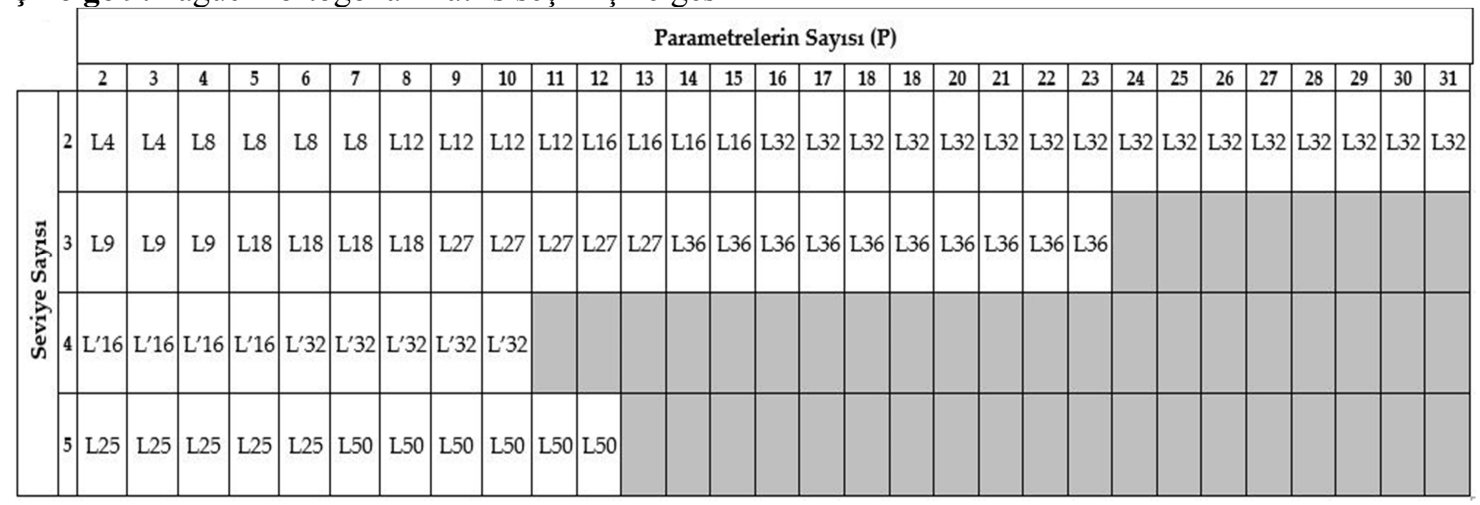

Çizelge 10. Çalışmada kullanılan faktörler ve seviyeler

\begin{tabular}{|l|c|c|c|}
\hline Seviyeler Faktörler & 1. Seviye & 2. Seviye & 3. Seviye \\
\hline Matkap Çapı (A) & $6,8 \mathrm{~mm}_{(1)}$ & $9 \mathrm{~mm}_{(2)}$ & $9,6 \mathrm{~mm}_{(3)}$ \\
\hline Kesme Hızı (Vc) (B) & $60 \mathrm{~m} / \mathrm{dk}_{(1)}$ & $70 \mathrm{~m} / \mathrm{dk}_{(2)}$ & $80 \mathrm{~m} / \mathrm{dk}_{(3)}$ \\
\hline İlerleme Hız (f) (C) & $0,10 \mathrm{~mm} / \operatorname{dev}_{(1)}$ & $0,15 \mathrm{~mm} / \mathrm{dev}_{(2)}$ & $0,20 \mathrm{~mm} / \operatorname{dev}_{(3)}$ \\
\hline Malzeme Sertliği (Brinell Sertliği) (D) & $180-240 \mathrm{HB}_{(1)}$ & $135-180 \mathrm{HB}$ & - \\
\hline
\end{tabular}

Cizelge 11'de Taguchi $\mathrm{L}_{9}$ ortogonal deney tasarım matrisi tanımlanmıştır. Kontrol faktörü olan matkap çapı, malzeme cinsi ve devir sayısı yerine A, B, C, D harflerini, kontrol unsurlarının seviyelerini belirlemek için 1, 2, 3 sayıları kullanılarak Çizelge 11, Çizelge 12 ile verilen matris formunda ifade edilmiştir.

Çizelge 11. Taguchi $\mathrm{L}_{9}$ ortogonal deney tasarım matrisinin tanımlanması

\begin{tabular}{|c|c|c|c|c|}
\hline $\begin{array}{l}\text { Deney } \\
\text { siras1 }\end{array}$ & $\begin{array}{l}\text { Matkap } \\
\text { Çapı } \\
\text { (A)mm }\end{array}$ & $\begin{array}{c}\text { Kesme } \\
\text { Hizi } \\
\text { Vc } \\
\text { (B) }\end{array}$ & $\begin{array}{l}\text { İlerleme } \\
\text { Hzz, f } \\
\text { (C) }\end{array}$ & $\begin{array}{l}\text { Malzeme } \\
\text { Sertliği } \\
\text { (D) }\end{array}$ \\
\hline Deney 1 & $6,8_{(1)}$ & $60_{(1)}$ & $0,10_{(1)}$ & $180-240 \mathrm{HB}_{(1)}$ \\
\hline Deney 2 & $6,8_{(1)}$ & $70_{(2)}$ & $0,15_{(2)}$ & $135-180 \mathrm{HB}_{(2)}$ \\
\hline Deney 3 & $6,8_{(1)}$ & $80_{(3)}$ & $0,20_{(3)}$ & $180-240 \mathrm{HB}_{(1)}$ \\
\hline Deney 4 & $9_{(2)}$ & $60_{(1)}$ & $0,15_{(2)}$ & $135-180 \mathrm{HB}_{(2)}$ \\
\hline Deney 5 & $9_{(2)}$ & $70_{(2)}$ & $0,20_{(3)}$ & $180-240 \mathrm{HB}_{(1)}$ \\
\hline Deney 6 & $9_{(2)}$ & $80_{(3)}$ & $0,10_{(1)}$ & $135-180 \mathrm{HB}(2)$ \\
\hline Deney 7 & $9,6_{(3)}$ & $60_{(1)}$ & $0,20_{(3)}$ & $135-180 \mathrm{HB}_{(2)}$ \\
\hline Deney 8 & $9,6_{(3)}$ & $70_{(2)}$ & $0,10_{(1)}$ & $180-240 \mathrm{HB}_{(1)}$ \\
\hline Deney 9 & $9,6_{(3)}$ & $80_{(3)}$ & $0,15_{(2)}$ & $180-240 \mathrm{HB}(1)$ \\
\hline
\end{tabular}

Çizelge 12. Taguchi $\mathrm{L}_{9}$ ortogonal deney tasarım matrisi

\begin{tabular}{|c|c|c|c|c|}
\hline \multirow{2}{*}{ Deney No } & \multicolumn{4}{|c|}{ Sütunlar } \\
\cline { 2 - 5 } & A & B & C & D \\
\hline 1 & 1 & 1 & 1 & 1 \\
\hline 2 & 1 & 2 & 2 & 2 \\
\hline 3 & 1 & 3 & 3 & 3 \\
\hline 4 & 2 & 1 & 2 & 3 \\
\hline 5 & 2 & 2 & 3 & 1 \\
\hline 6 & 2 & 3 & 1 & 2 \\
\hline 7 & 3 & 1 & 3 & 2 \\
\hline 8 & 3 & 2 & 1 & 3 \\
\hline 9 & 3 & 3 & 2 & 1 \\
\hline
\end{tabular}

Deneylerde ortaya çıkan değerler ile aşınma oranı ve tipi üzerine seviye ve unsurların etkisini görmek için Minitab 18 paket programı ile S/N yani S/G ve varyans analizi uygulanmıștır. Aşınma oranı ve $\mathrm{S} / \mathrm{G}$ oranlarının hesaplanmasında, aşınma miktarı en düşük seviyeye indirilmeye çalışıldığından "en küçük en iyi” karakteristiği kullanılmıştır. 


\subsection{Deney Sistemi}

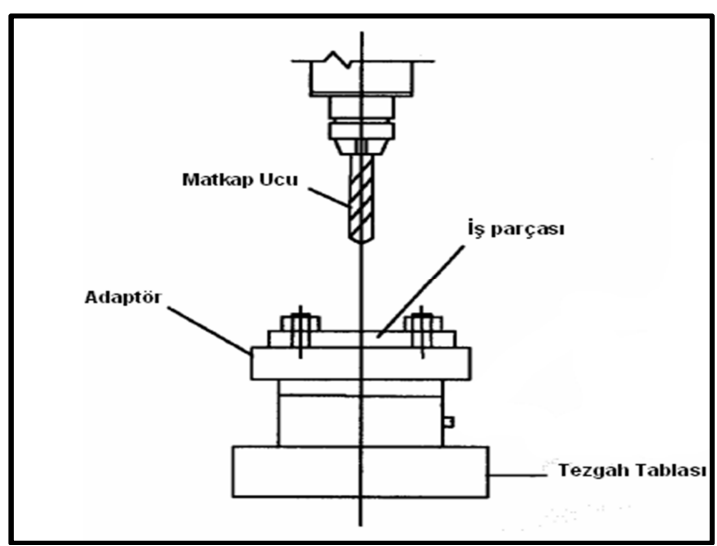

Şekil 1. Deney düzeneği

Delik delme operasyonu EKÇELIK M-13 adlı matkap tezgahında gerçekleşmiştir. Çizelge 11 'de görüldüğü üzere dokuz adet deney gerçekleştirilmiştir. Her bir deney için 20 defa 10 $\mathrm{mm}$ derinliğinde delme işlemi yapılmıştır. Toplamda 180 adet delme işlemi yapılmıştır. Deney sonuçları, S/G oranı ve tüm faktörlerin aşınma miktarı üzerine olan etkileri, Minitab 18 paket programıyla ölçülüp grafiksel hale getirilmiştir. Her 20 delikte bir çekilen fotoğraflarla takımlarda meydana gelen aşınmalar takım ölçme ve ayarlama makinasına adapte edilen kameralı görüntüleme sistemi ile görüntülenmiştir. Daha sonra, matkap uçlarının ağırlığı hassas terazi vasıtasıyla ölçülmüştür.

\section{BULGULAR VE TARTIŞMA}

\subsection{Kesici Takım \\ Değerlendirilmesi}

Aşınmalarının

Takımların farklı çaplar, farklı ilerleme hızları ve kesme hizlarının kombinasyonları sonucu meydana gelen deformasyonlar genellikle serbest yüzey aşınması, kesici kenardan tanecik kopması, kesici uç aşınması olarak belirlenmiştir. Her deneye göre meydana gelen aşınma tipleri şekillerde verilmiş olup, aşınma miktarları ağırlıkça belirlenmiştir. Şekil 2'de kullanılmamış matkap uçları, Şekil 3, Şekil 4 ve Şekil 5'te sırasıyla deneylerden sonra alınan kamera görüntüleri görülmektedir.
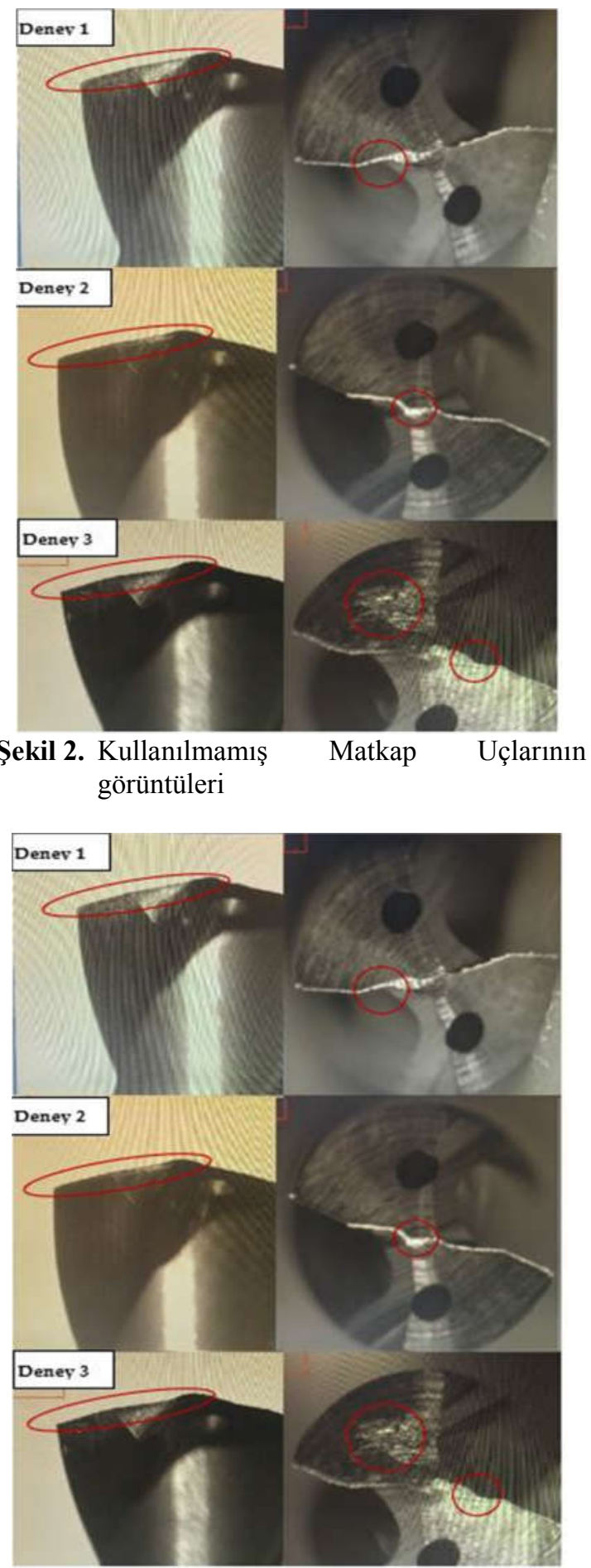

Şekil 3. Çapı $6,8 \mathrm{~mm}$ olan takımın deney sonrası görüntüleri 


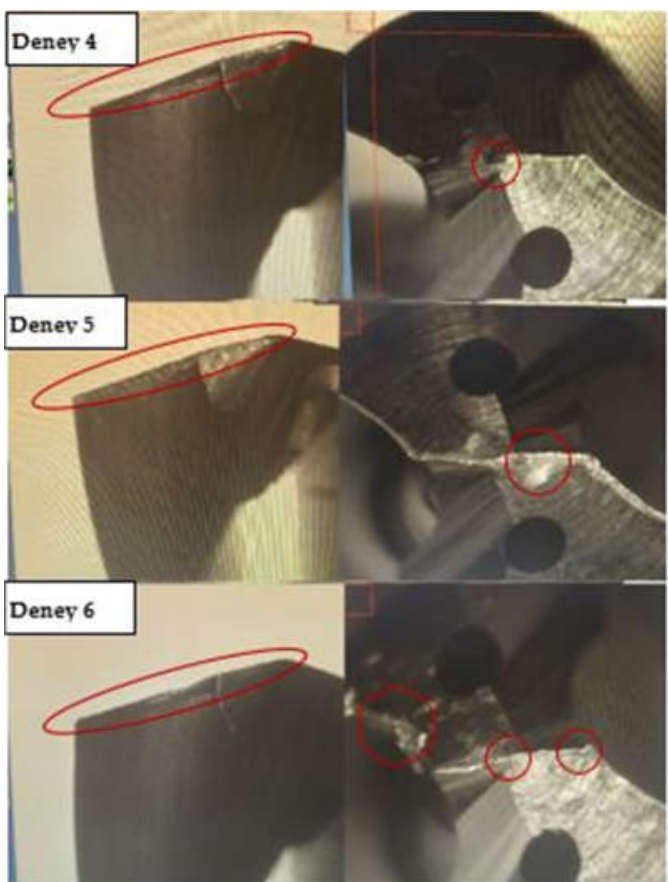

Şekil 4. Çapı 9,0 mm olan takımın deney sonrası görüntüleri

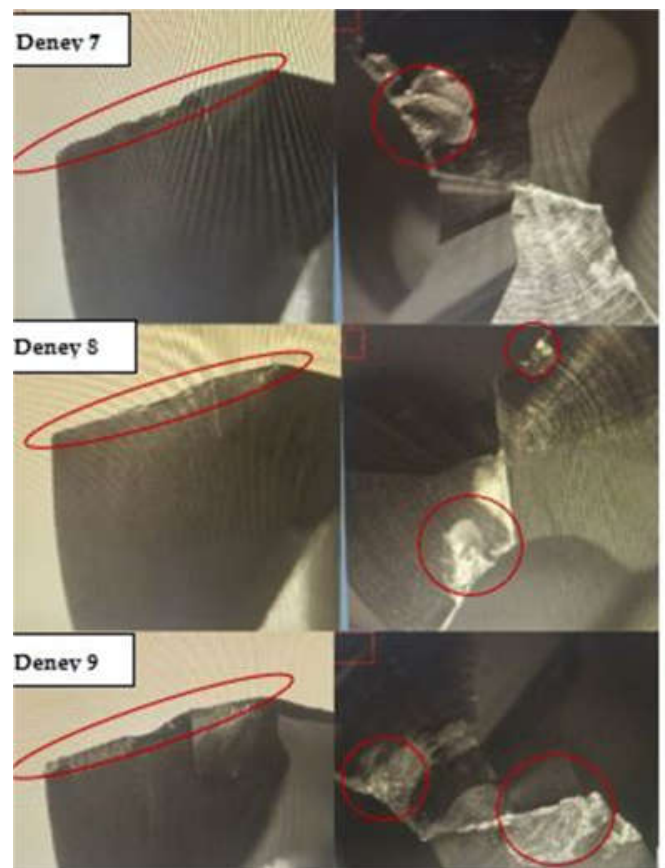

Şekil 5. Çapı 9,6 mm olan takımın deney sonrası görüntüleri
Çapı 6,8 mm olan takıma uygulanan deneyler Deney 1, Deney 2 ve Deney 3'tür. Çapı $9 \mathrm{~mm}$ olan takıma uygulanan deneyler ise Deney 4, Deney 5 ve Deney 6'dır. Çapı 9,6 $\mathrm{mm}$ olan takıma uygulanan deneyler ise Deney 7 , Deney 8 ve Deney 9'dur (Şekil 6).

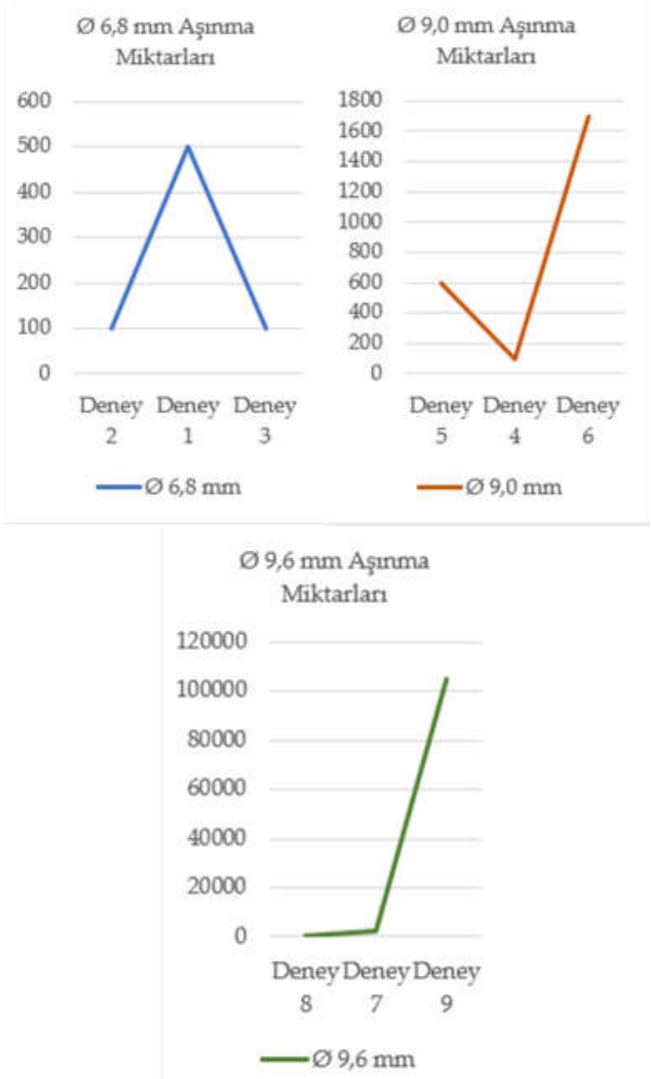

Şekil 6. Matkap uçlarındaki aşınma miktarları

Matkap uçlarının kullanılmamış ağırlıkları ve deneylerin sonunda ölçülen ağırlıkları Çizelge 13 'de görülmektedir. $\mathrm{Bu}$ görüntülere (Şekil 3-5) göre, 6,8 mm çaplı matkap ucunda en az aşınma miktarı gözlemlenirken $9,6 \mathrm{~mm}$ çapa sahip matkap ucu en fazla aşınan takım olmuştur. Yan kesici kenar aşınması bütün takımlarda görülmüştür ve ilerleme miktarının artması ile orantılı olduğu tespit edilmiştir. Kesici uç aşınması bütün takımlarda görülmekle beraber en çok karşılaşılan aşınma türü kesici kenardan tanecik kopmasıdır ve $9 \mathrm{~mm}$ ve 9,6 mm çapa sahip matkap 
uçlarında fazlasıyla görülmektedir. Kesici kenardan tanecik kopmasının kesme hızının artması ile orantılı olarak arttığı gözlemlenmiştir. $\mathrm{Bu}$ durum kesme hızının artması ile takıma gelen yüklerin arttığının göstergesidir. Benzer çalışmalarda da kesme hızlarının matkap aşınmasını az miktarda etkilediği bilinmektedir. Matkap uçlarının ağırlıklarının ölçümünde en çok ağırlık kaybına sebebiyet veren aşınma türü kesici kenardan tanecik kopması iken en az ağırlık kaybına yol açan aşınma türü kesici uç aşınması olmuştur. Literatürde, GGG 50 malzemelerde yapılan denemelerde genelde bütün takımlarda radyal ağız aşınması ve dış köşe aşınması gözlenmiştir ancak ilerlemede yapılan artışlarla en çok radyal ağız aşınmaları tespit edildiği bulguları mevcuttur [16]. Yapılan bu çalışmalarda farklı malzeme ve devirlerde yapılmış olsa da yapılan deneysel çalışmalarla benzer nitelikte sonuçlar vermektedir. Aynı şekilde başka bir malzeme üzerinde yapılan çalışmalarda yine karbür takımlarda kaplamalı ve kaplamasız olarak yapılan denemelerde daha düşük hızlarda yapılmış bir çalışma olmasına rağmen benzer aşınma trendleri görüldüğü belirtilmiştir [17]. $\mathrm{Bu}$ da yapılan çalışma ve taguchi metodu ile belirlenen değerlerimizin aynı zamanda elde edilen sonuçların doğruluğunu göstermektedir.
Çizelge 13. Matkap uçlarının deneyler sonucu ağırlık ölçümü

\begin{tabular}{|l|c|c|c|}
\hline & $\begin{array}{c}\text { İk Ağırlık } \\
\text { (g) }\end{array}$ & $\begin{array}{c}\text { Son Ağırlık } \\
\text { (g) }\end{array}$ & $\begin{array}{c}\text { Ağırlık } \\
\text { Kaybı (g) }\end{array}$ \\
\hline $\begin{array}{l}\text { 6,8 mm çaptaki } \\
\text { matkapın deney } \\
\text { sonuçları }\end{array}$ & 40,2117 & 40,2110 & 0,0007 \\
\hline $\begin{array}{l}\text { 9 mm çaptaki } \\
\text { matkapın deney } \\
\text { sonuçları }\end{array}$ & 75,5309 & 75,5285 & 0,0024 \\
\hline $\begin{array}{l}\text { 9,6 mm çaptaki } \\
\text { matkapın deney } \\
\text { sonuçları }\end{array}$ & 69,6416 & 69,5345 & 0,1071 \\
\hline
\end{tabular}

\subsection{Sinyal/Gürültü Oranı ve Varyans Analizi (S/N Ratio and ANOVA)}

Yapılan çalışmaya konu olan matkap takımlarında görülen karakteristik değer aşınma miktarı olduğu için ve aşınma miktarının en az olması istendiği için deneylerin analizinde "düşük değer iyi" yaklaşımına göre hesaplanan $\mathrm{S} / \mathrm{G}$ oranı kullanılacaktır. Şekil 7'de Taguchi L9 Deney Tasarımına göre $\mathrm{S} / \mathrm{G}$ oranları verilmiştir. Her unsur için belirlenen en yüksek $\mathrm{S} / \mathrm{G}$ oranı en iyi deney sonucuna, yani aşınma miktarının en az olduğu sonucu belirtir.

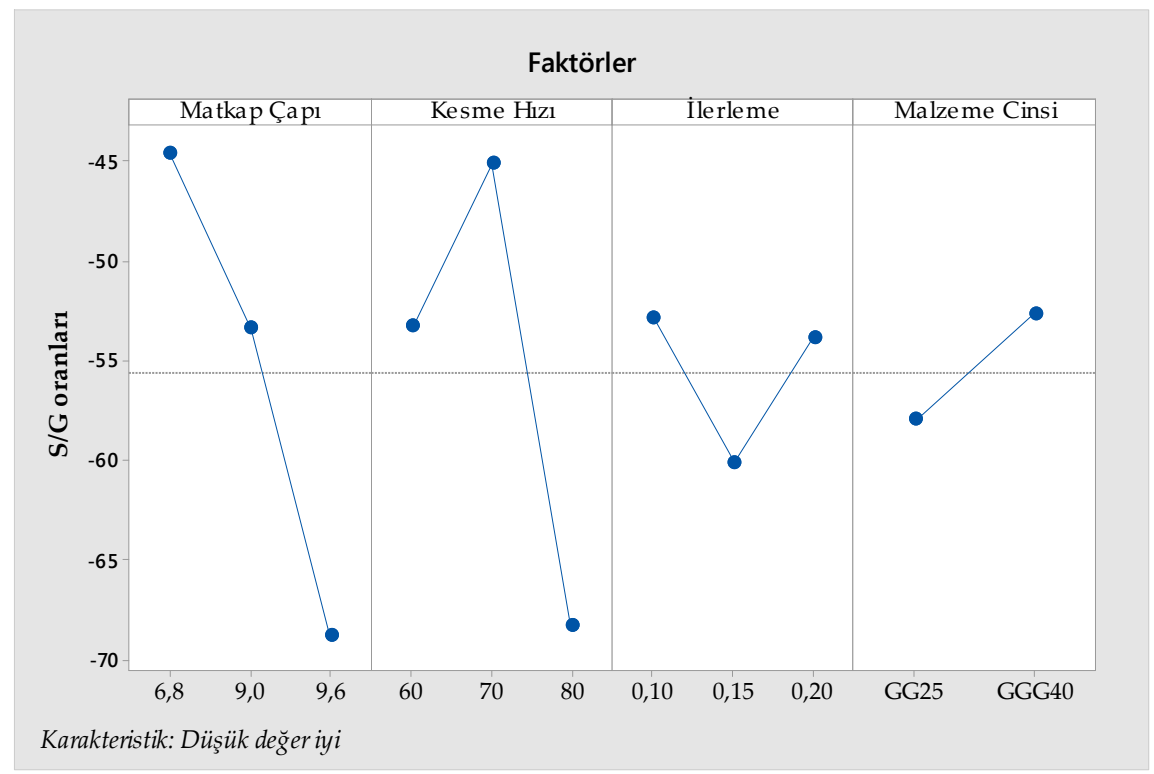

Şekil 7. Tüm faktör ve seviyelerin $\mathrm{S} / \mathrm{G}$ üzerine etkileri 
Şekil 7'deki grafiklerde de görüldüğü gibi her bir faktör için $\mathrm{S} / \mathrm{G}$ oranının en yüksek olduğu seviyeler matkap çapında $6,8 \mathrm{~mm}$, kesme hızında $70 \mathrm{~m} /$ dak, ilerlemede $0,10 \mathrm{~mm} / \mathrm{dev}$, malzeme cinsinde ise GGG40 olarak gözükmektedir. Böylelikle, en uygun nokta olarak tavsiye edilen kombinasyon $6,8 \mathrm{~mm}$ çaplı matkap ucu ile $70 \mathrm{~m} /$ dak kesme hızı ve $0,10 \mathrm{~mm} / \mathrm{dev}$ ilerleme ile GGG40 standartlı malzeme olmaktadır.
Varyans analizinde hedeflenen, incelenen unsurların, kaliteyi ölçebilmek için seçilen çıktı değerini (aşınma miktarı) hangi miktarda etkilediklerini ve farklı seviyelerin nasıl bir değişkenliğe sebep olduklarını göstermektedir. Çizelge $14^{\prime}$ 'de deney tasarımına göre varyans analizi sonuçları verilmiştir.

Çizelge 14. Varyans analiz sonuçları

\begin{tabular}{|l|c|c|c|c|c|}
\hline & $\begin{array}{c}\text { Serbestlik } \\
\text { Derecesi }\end{array}$ & $\begin{array}{c}\text { Karelerin } \\
\text { Toplamı }\end{array}$ & $\begin{array}{c}\text { Ortalama } \\
\text { Karelerin } \\
\text { Toplam }\end{array}$ & F & $\begin{array}{c}\text { Faktör Etkisi } \\
(\%)\end{array}$ \\
\hline Matkap Çap1 & 2 & 897,6 & 438,17 & 0,35 & $28,27 \%$ \\
\hline Kesme Hız1 & 2 & 827,91 & 402,87 & 0,32 & $26,08 \%$ \\
\hline İlerleme & 2 & 1265,41 & 1265,75 & 0,06 & $31,94 \%$ \\
\hline Malzeme Cinsi & 1 & 133,38 & 130,38 & 0,07 & $13,85 \%$ \\
\hline Hatalar & 1 & 50,69 & 36,69 & & $2,86 \%$ \\
\hline Toplam & 8 & 3174,99 & & & $100,00 \%$ \\
\hline
\end{tabular}

Analiz sonuçlarının istatistiksel olarak doğruluğu da test edilir. Buna göre ilk olarak $S / G$ oranının toplam değișkenliğini belirten SST değeri (toplam karelerin toplamı) hesaplanır. SST değeri üç unsurun ayr1 ayrı olarak karelerinin toplamı değerleri (SSA, SSB ve SSC) ile hata payının karelerinin toplamı olan $\mathrm{SSe}$ değerinin toplamından oluşmaktadır. Her unsurun karelerinin toplamının ayrı olarak hesaplanması sonucu ortaya çıkan sonuçlar Çizelge 14'de gösterilmiş̧ir. Çizelgeye göre yüzey pürüzlülüğ̈ünün değerlendirilmesi sonucunda matkap çapı $(\% 28,27)$, kesme hizı $(\% 26,08)$, ilerleme $(\% 31,94)$, malzeme cinsi $(\% 13,85)$ ve hata $(\% 2,86)$ faktörlerinin etkileri belirtilmiştir. Bu verilere göre ilerleme faktörü yüzey pürüzlülüğünü etkileyen en önemli faktördür.

\section{SONUÇ}

GG25 ve GGG40 malzemelerin farklı çaplarda takımlarla işlenmesinde;

1. Bütün takımlarda birden fazla aşınma türü görülmüştür. Aşınma tipleri, serbest yüzey aşınması, kesici uç aşınması ve kesme kenarından tanecik kopmasıdır.
2. Kesici kenardan tanecik kopması, en çok çap 19,6 mm olan takımda görülmüştür.

3. GGG40 malzemenin GG25 standartl malzemeye göre, matkap ucunda daha çok aşınmaya sebebiyet verdiği görülmüştür.

4. Çapı $6,8 \mathrm{~mm}$ olan takımda 3 deney sonunda 700 mikrogramlık aşınma, çapı $9 \mathrm{~mm}$ olan takımda 3 deney sonunda 2400 mikrogramlık aşınma ve çap1 $9,6 \mathrm{~mm}$ olan takımda ise 3 deney sonunda 107100 mikrogramlık aşınma olduğu ölçülmüştür. Matkap ucunun çapı arttıkça aşınma miktarlarında da artış gözlemlenmiştir.

5. Kesici kenardan tanecik kopması kesici takım çapının ve ilerlemenin artışına bağlı olarak arttı̆̆g gözlemlenmiş̧tir.

6. $9,6 \mathrm{~mm}$ çapa sahip takımda aşınmanın yüksek oluşu fotoğraflarda da görüldüğü üzere parçacık kopmasından kaynaklıdır.

7. Deneyler incelendiğinde, sıkça görülen aşınma tiplerinden biri olan serbest yüzey aşınması her deney sonu takım ölçme ve ayarlama makinası ile gözlenmiştir. Bir diğer aşınma tiplerinden olan tanecik kopması/çentiklenmesi Deney1, Deney 6, 
Deney 7 ve Deney 8 'de görülmüștür. Kesici uç aşınması ise Deney 4, Deney 5 ve Deney 9 da gözlemlenmiştir.

\section{KAYNAKLAR}

1. Uluğ, D., 2014. Kaplamalı ve Kaplamasız Sementit Karbür Takımlar için Taylor Takım Ömrü Modelindeki “n” Üstel Değerinin Deneysel Olarak Araştırılması, Yüksek Lisans Tezi, Gazi Üniversitesi Fen Bilimleri Enstitüsü, Ankara.

2. İşbilir, Ö., 2008. Talaş Kaldırmada Değişken Yüklemenin Takım Ömrüne Etkisinin Belirlenmesi, Yüksek Lisans Tezi, Ege Üniversitesi Fen Bilimleri Enstitüsü, İzmir

3. Karayel, B., Nalvant, M., 2014. Ç4140 Malzemesinin Tornalamasinda İlerleme, Kesme Hızı ve Kesici Takımın Yüzey Pürüzlülüğü, Takım Ömrü ve Aşınmaya Etkileri, Makine Teknolojileri Dergisi, 11(3), 11-26.

4. Tekelsan, Ö., Gerger, N., 2008. AISI 304 Östenitik Paslanmaz Çeliklerde Kesme Parametrelerine Bağlı Olarak Yüzey Pürüzlülüklerinin Araştırılması, BAÜ FBE Dergisi, 10, 3-12.

5. Ertunç, H.M., 2001. Kesici Takımların Aşınmasını Gözlemleme Üzerine Yapılan Çalışmalar, Mühendislik Bilimleri Dergisi, 7, 55-62.

6. Kuram, E., Özcelik, B., 2017. Optimization of Machining Parameters During Micro-milling of ti6al4v Titanium Alloy and Inconel 718 Materials Using Taguchi Method. Proceedings of the Institution of Mechanical Engineers, Part B: Journal of Engineering Manufacture, 231(2), 228-242.

7. Rathod, B.S., Khedkar, N.K., Jatti, V.K.S., 2014. Optimization of Turning Process Parameters for Surface Roughness and MRR Based on the Taguchi Method During Machining of Inconel-718. International Journal of Applied Engineering Research, 9(1), 83-92.

8. Roy, R.K., 2010. A Primer on the Taguchi Method, $2^{\text {nd }}$ Edition, Society of Manufacturing Engineers, Michigan.
9. Thirumalai, R., Senthilkumaar, J., Selvarani, P., Ramesh, S., 2013. Machining Characteristics of Inconel 718 Under Several Cutting Conditions Based on Taguchi Method. Proceedings of the Institution of Mechanical Engineers, Part C: Journal of Mechanical Engineering Science, 227(9), 1889-1897.

10. Bayraktar, Ş., Siyambaş, Y., Turgut, Y., 2017. Delik Delme Prosesi: Bir Araştırma, Sakarya Üniversitesi Fen Bilimleri Enstitüsü Dergisi, 21(2), 120-130.

11. Montgomery, D.C., 2001. Design and Analysis of Experiments, 5. Bask1, John Wiley, Wiley Sons, New York.

12. Şirvanc1, M., 1997. Kalite İçin Deney Tasarımı "Taguchi Yaklaşımı", Literatür Yayıncılık Dağıtım Pazarlama San. ve Tic. Ltd. Şti., İstanbul.

13. Asiltürk, İ., Akkuş, İ., 2011. Determining the Effect of Cutting Parameters on Surface Roughness in Hard Turning Using the Taguchi Method. Measuremen, 44, 1697-1704.

14. Kıvak, T., Samtaş, G., Çiçek, A., 2012. Taguchi Method Based Optimisation of Drilling Parameters in Drilling of AISI 316 Steel with PVD Monolayer and Multilayer Coated HSS Drills. Measurement, 45(6), 1547-1557.

15. Ross, P.J., 1989. Taguchi Techniques for Quality Engineering, Loss Function, Orthogonal Experiments, Parameter and Tolerance Design, McGraw-Hill International Book Company, New York.

16. Yavuz, M., Gökçe, H., Şeker, U., 2017. Matkap Geometrisinin Takım Aşınması ve Talaş Oluşumu Üzerine Etkisinin Araştırılması, Gazi Mühendislik Bilimleri Dergisi, 3(1), 1-8.

17. Sharif, S., Rahim, E.A., 2007. Performance of Coated- and Uncoated-carbide Tools When Drilling Titanium Alloy, Journal of Materials Processing Technology, 185, 72-76. 